\title{
NOBLE GAS INCORPÚRATIONं IN SPUTTERED AND ION BEAM ASSISTED GROWN SILICON FILMS
}

* A. van Veen, Interfaculty Reactor Institute, Delft University of Technology, Mekelweg 15, NL-2629 JB Delft, The Netherlands.

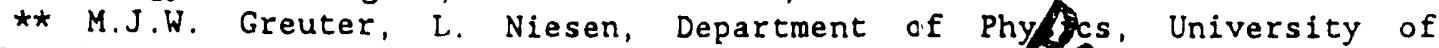
Groningen, Nijenborgh 4, NL-9747 AG Groningen, The Nethonds.

$\star \star \star *$ B. Nielsen, K.G. Lynn, Brookhaven National Laborator CFisysics Department, Upton NY, USA.

ABSTRACT

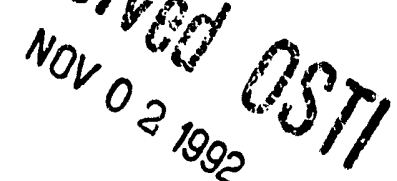

Gas desorption measurements have been performed on sputter deposited silicon films. The sputter gas was argon or krypton. Parameters influencing the incorporation process e.g. bias voltage, substrate temperature and arrival rate ratio of silicon and noble gas atoms have been systematically varied. The films, a-Si and $\mathrm{C}-\mathrm{Si}$, have been characterised by various techniques for composition and defect analysis. A model has been applied to describe the composition of the growing silicon layer. Underlying mechanisms like gas-gas sputtering have been studied in separate ion implantation experiments. For a-Si concentrations as high as $6 \% \mathrm{Ar}$ and $\mathrm{Kr}$ have been found. An important effect is the injection of self-interstitial atoms caused by the low energy heavy ion bombardment. It causes the layer to grow without large open volume defects.

\section{INTRODUCTION}

Low energy ion bombardment is employed to assist and control silicon film growth [1]. In sputter deposition a negative bias at the substrate causes a considerable flux of low energy (Ar)-ions hitting the growing film. In ion assisted $M B E$ an extra ion gun can provide the required ions. Beneficial effects on the growth process have been reported e.g. Ohmi et al [2] found growth of homoepitaxial Si-films at lower temperature compared to conventional thermal molecular epitaxy (MBE).

Chapman has reviewed the early work on thin film production by noble gas sputtering [3]. Gas release from sputtered silicon films has been reported by Taoufik et al [5] and van Veen et al [6]. Results on the basic incorporation processes of noble gas atoms in metals have been reported by Kornelsen [6], Edwards [7] and van Veen [8].

In this article experimental results are presented for gas incorporation in sputtered silicon films. It is tried to model the incorporotion process quantitatively.

\section{EXPERIMENTAL}

Thin films were produced by sputtering of silicon in a low pressure (0.01-0.1 Pa) argon or krypton plasma similarly as described in [8]. The standard energy of the noble gas ions striking the target was $1 \mathrm{keV}$ and the standard flux amounted to $6 \times 10^{16} \mathrm{~cm}^{-2} \mathrm{~s}^{-1}$. The blas voltage of the substrate could be varied from $0.300 \mathrm{~V}$, and the temperature could be controlled from $350-900 \mathrm{~K}$. The ion filux at the substrate varied from 0 . $10^{16} \mathrm{~cm}^{-2} \mathrm{~s}^{-1}$ depending on the bias voltage. The ion flux could be reduced without changing the plasma parameters by applying a pulsed bias voltage to the substrate (duty cycle from 10-100\%). The flux of sputtered silicon atoms arriving at the substrate was calibrated by means of a quartz crystal microbalance and by weighing of the deposited film. Films were deposited on 
an area of $10 \mathrm{~mm}$ diameter. In a modified setup for desorption studies a Si(111) single crystal of $6 \mathrm{~mm}$ diameter was used as substrate which could be heated to $1400 \mathrm{~K}$. A desorption apparatus equipped with a low energy ion beam facillty [8] was used to perform desorption studies on the elementary processes taking place during incorporation.

Some of the films were produced elsewhere in MBE-apparatus. Standard techniques EDS, RBS, NRA were used for ex-situ composition analysis. Structure analysis was performed by XRD. Positron beam analysis was used to characterise the defects in the films, in particular the open volume defects [9]. Mössbauer spectroscopy has been applied to probe the local environment of the incorporated krypton [10].

\section{INCORPORATION MODEL}

The incorporation of the noble gas atoms is initialiy caused by a process of implantation and trapping. Those atoms that survive subsequent processes as resputtering, of the film or gas-gas sputtering contribute to the final gas concentration. The steady-state concentration $c(x)$ in the growirg film is given by

$$
0=\frac{d c}{d t}=J_{A} I(x)+D \frac{d^{2} c}{d x^{2}}+V_{s} \frac{d c}{d x}-J_{A} \sigma_{g}(x) c(x
$$

with $J_{A}=$ flux of swift noble gas projectiles from the plasma attracted to the substrate; $V_{\mathbf{s}}=$ - net growth velocity $=\left(J_{A} Y_{\underline{3}}-J_{\underline{B}}\right) / N_{0}$, where $Y_{\underline{3}}$ is the sputtering yield of the noble gas particles and $J_{\underline{3}}$ the flux of sputtered atoms arriving at the film surface; $N_{0}$ is the atomic density; $I(x)$ - the probability of the noble gas being trapped at depth $x ; \eta=1 I(x) d x$ the integrated trapping probability; $\sigma_{B}(x)$ the cross section for gas release from the film by irradiation with noble gas ions; $D$ - the diffusivity (thermal or radiation enhanced). The above model takes into account the release of the noble gas atoms by the process of gas sputtering which is a defect-mediated release process. Tsai et al [1] describe defect and noble gas concentrations in deposited films exclusively by diffusion. The model of eq. 1 does not account for effects caused by high incorporated gas concentrations.

\section{RESULTS OF INCORPORATION EXPERIMENTS}

Typical desorption spectra obtained for sputter deposited films with argon are shown in figure 1 . Substrate temperatures were varied from RT to $600 \mathrm{~K}$. The release is centered at the temperature were crystallization of the film takes place. The release mechanism is simply explained by pushing the noble

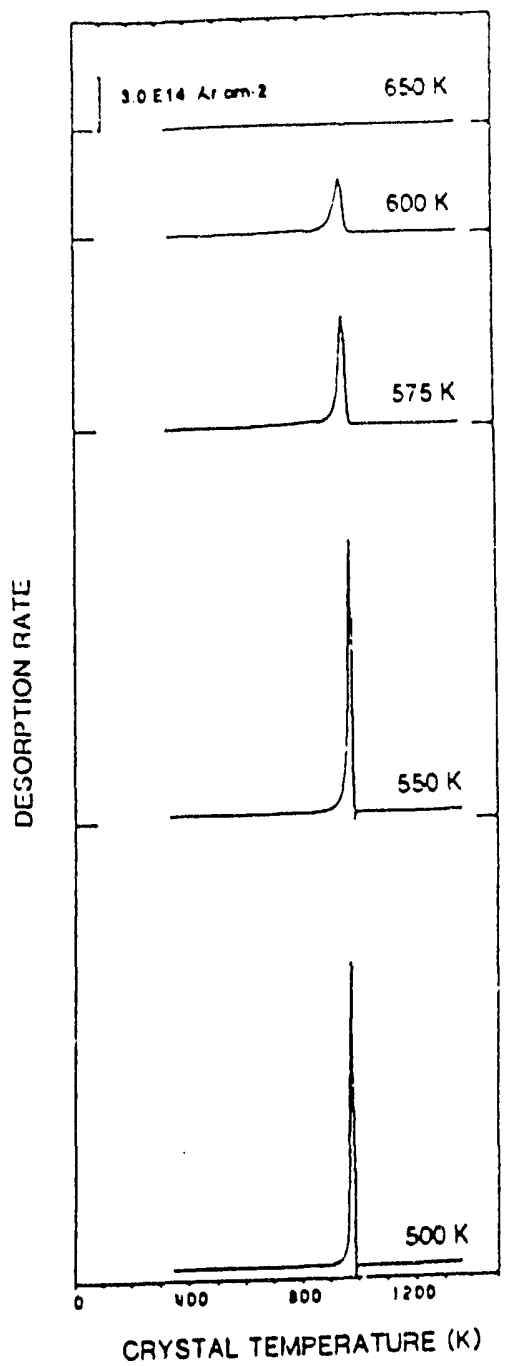

Figure 1. Argon desorption spectra obtained for a $45 \mathrm{~nm}$ thick sputtered Si-layers on a silicon (100) wafer at a bias voltage of $30 \mathrm{~V}$. The substrate temperature has been varied as indicated. The narrow peak at $970 \mathrm{~K}$ corresponds with crystallization.

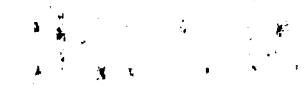




\section{DISCLAIMER}

This report was prepared as an account of work sponsored by an agency of the United States Government. Neither the United States Government nor any agency thereof, nor any of their employees, makes any warranty, express or implied, or assumes any legal liability or responsibility for the accuracy, completeness, or usefulness of any information, apparatus, product, or process disclosed, or represents that its use would not infringe privately owned rights. Reference herein to any specific commercial product, process, or service by trade name, trademark, manufacturer, or otherwise does not necessarily constitute or imply its endorsement, recommendation, or favoring by the United States Government or any agency thereof. The views and opinions of authors expressed herein do not necessarily state or reflect those of the United States Government or any agency thereof. 


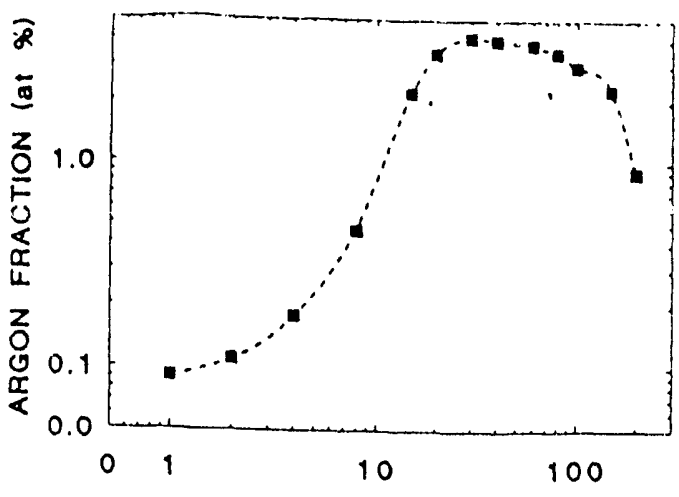

BIAS (V)

Figure 2. Argon concentration in sputter deposited silicon films vs substrate bias voltage.

In sputter deposited crystalline metal easier than from amorphous silicon. films accumulated noble gas concenrelease values of $0.2 \%$. These results inight indicate that mechanisms are much more effective for crystalline than for amorphous structures. For thick films it seems that at elevated temperatures the film grows at first crystalline but after having reached a thickness of about $500 \mathrm{~nm}$ (with a low gas concentration) the further growth proceeds as amorphous silicon with a high gas concentration. These observations were made with XRD, SEM (on cross sections), RBS and MEIS techniques. For $5 \mu \mathrm{m}$ thick krypton sputtered films RBS and EDS analyses showed concentrations up to $6 \%$ for $580 \mathrm{~K}$ deposited amorphous films and about $0.3 \%$ for films deposited at $850 \mathrm{~K}$.

Bias voltage varlation results shown in figure 2 indicate very high noble gas concentrations in the energy interval from 20-200 V. Apparently the penetration probability increases considerably at about $20 \mathrm{eV}$. At bias voltages $>50 \mathrm{eV}$ resputtering occurs causing a reduction of the net growth velocity and therefore a longer exposure of implanted gas atoms to depth dependent release processes.

The noble gas atom/sili. con flux ratio varied by using the pulsed bias mode yielded for krypton sputtered amorphous films, at $50 \mathrm{~V}$ bias, the concentrations shown in figure 3 . The maximum concentration is reached for a $\mathrm{Kr} / \mathrm{SI}$ flux ratio of 4 . Beyond this value release and sputter mechanisms counteract the noble gas accumulation.

Results of low energy penetration and trapping experiments performed on single crystalline silicon are shown in figure 4. It is observed that already at $20 \mathrm{eV}$ ion energy $5 \%$ of the ions and at $100 \mathrm{eV}$ the majority of noble gas lons is trapped. The argon desorption takes place in peaks which occur in the temperature inter. val from 400 to $830 \mathrm{~K}$. The peak at $830 \mathrm{~K}$ has been assigned by us to desorption of argon

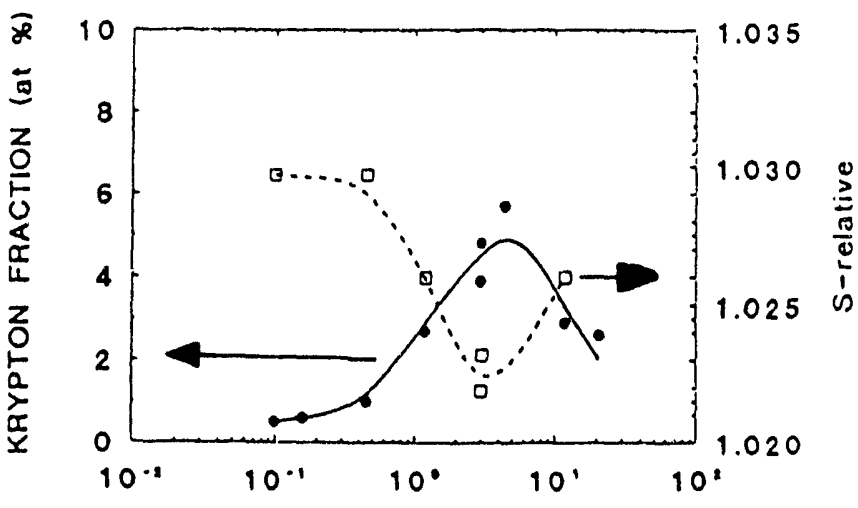

KRYPTON-SILICON ATOM RATIO

Figure 3. Krypton concentration and relative $S$-parameter measured for $5 \mu \mathrm{m}$ thick sputter deposited films vs the $\mathrm{Kr} / \mathrm{SI}$ flux ratio at $50 \mathrm{~V}$ bias and $580 \mathrm{~K}$ substrate tenperature. The solid line is the result of a model calculation with parameters given in the text. 


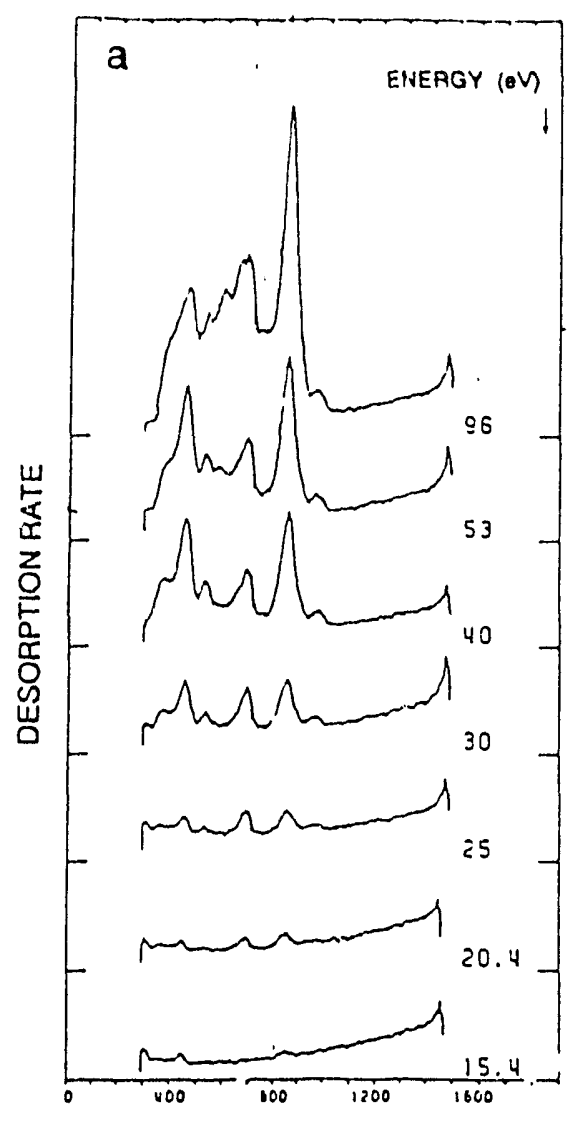

CRYSTAL TEMPERATURE

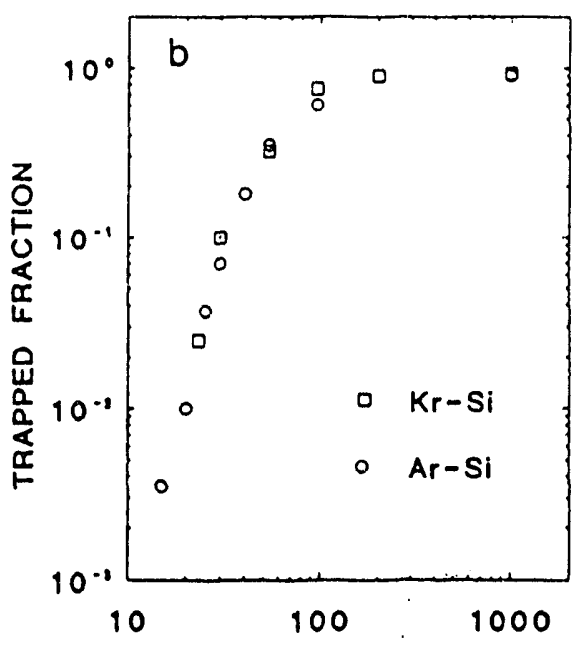

ION ENERGY (eV)

Figure 4. Desorption results obtained for $S i(111)$ irradiated with very low energy noble gas ions. a) $15-100 \mathrm{eV}$ $\mathrm{Ar}^{+}$-ions at a dose of $10^{13}$ $\mathrm{cm}^{-2}$. b) $\mathrm{Ar}$ - and $\mathrm{Kr}$-trapped fraction vs ion energy. from monovacancies. Thus at the elevated temperatures mentioned above a considerable fraction of the trapped gas will be thermally released. The remaining gas, i.e. substitutional noble gas atoms, is subject to athermal release processes.

Gas sputtering experiments have been performed on $100 \mathrm{eV} \mathrm{Kr}$ pre-implanted into crystalline silicon. Post-irradiation took place with low energy argon ions of energies of 50,100 and $500 \mathrm{eV}$. In this experiment two different noble gas ions have been used to distinguish the pre-implanted from the post-implanted noble gas atoms. Figure 5 shows the results. It is clearly observed that 1 . the amount of krypton is reduced, and 2. part of the krypton has been redistributed. The peak at $920 \mathrm{~K}$ (substitutional $\mathrm{Kr}$-atoms) and at $750 \mathrm{~K}$ is reduced, but some growth occurs of a peak at low temperature indicating clustering of krypton. Similar effects have been observed by us for noble gases in metals [11]. Mobile self-interstitial atoms (SIA) injected by the argon ions were found responsible for kick out reactions as follows: $\mathrm{KrV}$ (substitutional) + $\mathrm{I}$ (SIA) $\rightarrow \mathrm{Kr}$ (mobile interstitial). The cross sections for gas sputtering derived from the dose variation are of the same order of magnitude as found earlier for metals. Therefore it is likely that also in silicon above mechanism is operating.

For the depth dependence of the gas sputtering we used the expression $\sigma_{B}=\sigma_{0}$ $\exp \left(-x / \lambda_{3}\right)$ with $\lambda_{3}$ as the attenuation length for gas sputtering corresponding with the escape depth of interstitial noble gas. From the trapping saturation of low energy implanted noble gas measured for high doses it was derived that the escape depth amounted to a constant value of $0.5 \mathrm{~nm}$, and that the cross sections were $0.4,1.0$ and $2.5 \quad 10^{-14} \mathrm{~cm}_{2}$ res pectively for 50,100 and $500 \mathrm{eV}$ ions. For the sputter deposition experiments we obtained a satisfactory description when the model parameters in eq. 1 were chosen in line with the above parameters for c-Si; $\eta$ $-0.035 ; \lambda_{\mathrm{s}}=0.59 \mathrm{~nm} ; \sigma_{0}=1.34 \times 10^{-15} \mathrm{~cm}^{-2}$. The trapping factor $\eta$ is a factor of 10 lower than that in $\mathrm{C}-\mathrm{Si}$ because considerable thermal desorption of $50 \mathrm{eV}$ implanted Ar in a-Si takes place at $580 \mathrm{~K}$. Also the gas sputtering cross section is a factor of 3 lower than derived for single c-Si. This may be explained by the reduied depth of penetration of "interstitial utoms" in a-Si compared to c-Si. 


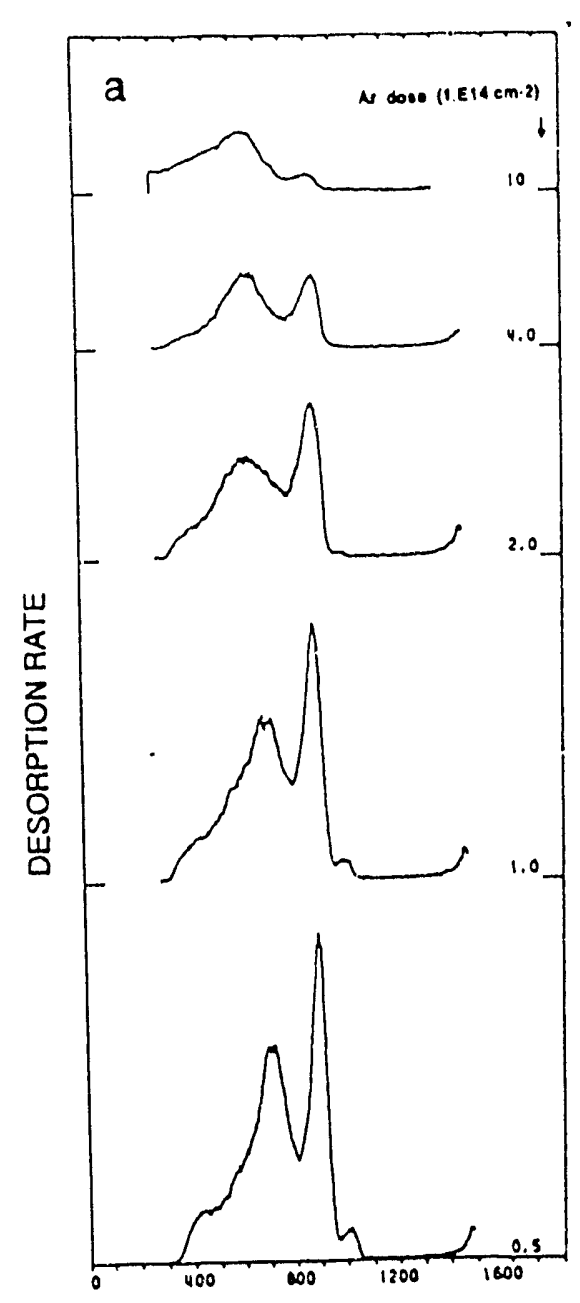

CRYSTAL TEMPERATURE

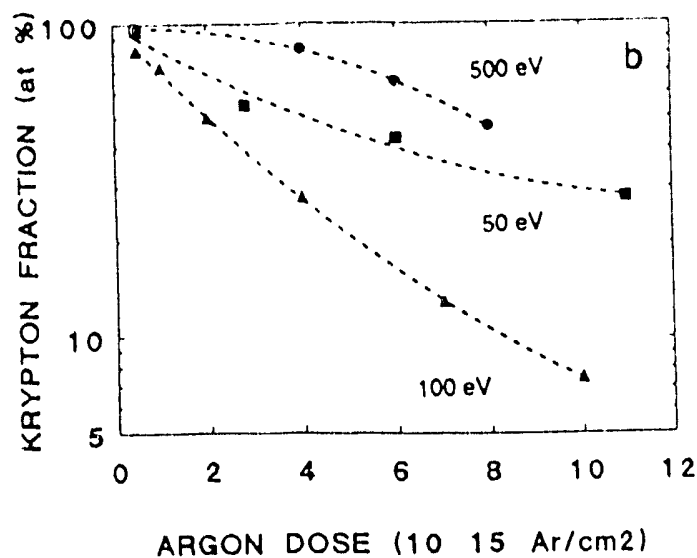

Figure 5. a) $\mathrm{Kr}$-desorption spectra for $S i(111)$ irradiated with $100 \mathrm{eV}$ $\mathrm{Kr}^{+} 1 \times 10^{13} \mathrm{~cm}^{-2}$ and post-irradiated with $100 \mathrm{eV} \mathrm{Ar}$ at the Indicated doses. b) Trapped fraction of $\mathrm{Kr}$ vs the argon post-irradiation dose for 50,100 and $500 \mathrm{eV}$.

Positron beam analysis $[12,13]$ was performed on the krypton sputtered silicon layers. The values of the relative $S_{r}$ parameter (for crystalline $S 1 S_{r}-1$ ) are shown in figure 3. Basically observation of a high $S$-value indicates the presence of open volume defects. Very large voids (100 $\mathrm{nm}$ stze) yield $\mathrm{S}_{5}-1.10$; small vacancy type defects $S_{y}-1.02$. The latter value has also been observed for $750 \mathrm{~K}$ annealed amorphous silicon obtained by $\mathrm{SI}$ ion bombardment [14]. The $S_{r}$-values found

for the sputtered films are similar. It is worth noting that $S_{r}$ is reduced with the increase of the krypton-content of the film. Values of $S_{r}$ for molecular beam deposited amorphous silicon (at $250^{\circ} \mathrm{C}$ ) are very high, $S_{x}=$ 1.14, which indicates large microcavities. Thus the positron results indicate clearly that ion assisted growth leads to a strong reduction of open volume defects.

Results obtained for silicon films grown by assistance of a $70 \mathrm{eV}$ $\mathrm{Ar}^{+}-1$ ion beaw [15] indicate that no open volume defects have been formed during the IBAD process. The $e^{+}$diffusion length is shorter than that observed for defect free and field free S1, indicating some $e^{+}$trapping or the presence of an electric field. In case of $e^{+}$trapping it would have to be a trap at whicl annihilation took place with characteristics quite similar to that of bulk S1, which is not the case for any "pure" openvolume defects. It seems therefore reasonable to assume that the majority of defects in this case would be Ar related such as ArV.

For the first time Mossbauer spectrescopy was applied to $\mathrm{Kr}$-inclusions in Si using the $9.4 \mathrm{keV}$ transition $1 \mathrm{n}{ }^{\circ} \mathrm{Kr}$. As an absorber we used $9 \mu \mathrm{m}$ thick Si-layers containing 6 at $\%$ of ${ }^{3} \mathrm{Kr}$ deposited on $15 \mu \mathrm{m}$ thick $\mathrm{Al}$ foils. The source was dehydrated 'RbI $[10]$. Preliminary results show that when fitted with a single line and a quadrupole split component and taking into account the quadrupole split nature of the source the spectra show an 1somer shift which cannot be explained by a pressure induced reduction of the electron density. Vartation of the absorber temperature from 4.2 to 200 $K$ does not show a significant change in the recollless fraction of both 
components indicating that the characteristic Debije temperature mist be much larger than $200 \mathrm{~K}$. Measurements as a function of the annealing temperature are currently in progress.

\section{CONCLUSION}

Experiments on the incorporation of noble gas in (sputter) deposited films assisted by ion bombardment and low energy implantation experiments demonstrate the important effects caused by the simultaneous injection of Si-atoms (self-interstitials). Open volume defects are reduced or removed by these interstitials and substitutional atoms are converted into higher mobile interstitial gas atoms which will be redistributed or released. A quantitative model is given which describes the incorporation. Low energy noble gas ions are rather easily trapped in silicon. High concentrations found in a-Si are explained by a less effective kick out mechanism for noble gas atoms and less thermal mobility than in c-Si.

Acknowledgement - K.T. Westerduin, dr. H. Schut and ir. R.A. Hakvoort are acknowledged for performing TDS and PA experiments. Work done at BNL, performed under DOE contract: DE-AC02-76CHOOO16.

\section{REFERENCES}

[1] C.J. Tsai, H.A. Atwater, T. Vreeland, Appl. Phys. Lett. 57, 2305 (1990)

[2] T. Ohmi, K. Hashimoto, M. Morita, T. Shibata, J. Appl. Phys. 69, 2062 (1991)

[3] B.N. Chapman, Glow Discharge Processes; Sputtering and Plasma Etching, John Wiley and Sons Inc., New York (1980)

(4) A. Taoufik, A. Chouiyakh, B. Lang, Radiation Effects 104, 117 (1987)

[5] A. van Veen, P.C. de Jong, K.R. Bijkerk, H.A. Filius and J.H. Evans, In: Fundamentals of Beam-Solid Interactions and Transient Thermal Processing, eds. M.J. Aziz, L.E. Rehn and B. Stritzker, Mat. Res.

Soc, Proc. 100, Boston, MA, pp 231-236 (1988)

[6] E.V. Kornelsen and M.K. Sinha, J. Appl. Phys. 39, 4546 (1968)

[7] D. Edwards Jr., J. Appl. Phys. 46, 1437 (1975)

[8] A. van Veen In: Erosion and Growth of Solids stimulated by Atom and Ion Beams, eds. G. Kiriakidis, G. Carter and J.L. Whitton, NATO ASI series E-No 112, M. Ni jhoff Publ., Dordrecht, Pp 200-221 (1986)

[9] K.R. B1jkerk, A. van Veen, G.J. van der Kolk and T. Minemura, J. Less Common Metals, 145, 189 (1988)

[10] M.J.W. Greuter, G.L. Zhang, L. Niesen, F.J.M. Buters and A. van Veen, In: Fundamental Aspects of Inert Gases in Solids, eds. S.E. Donnelly and J.H. Evans, NATO ASI Sertes B: Physics Vol. 279, Plenum Press, New York, pp 231-242 (1991)

[11] A. van Vene, G.J. van der Kolk, H.A. Filius, K.T. Westerduin and L.M. Caspers, Nucl. Instr. Meth., B 230, 779 (1984)

[12] P.J. Schultz and K.G. Lynn, Rev. Mod. Phys. 60, 701 (1988)

[13] A. van Veen, J. Trace and Microprobe Techn. 8, 1 (1990);

H. Schut, A Variable Energy Positron Beam Facility with Applications in Naterials Science. Thesis, Delft University of Technology (1990)

[14] S. Roorda, J.M. Poate, D.C. Jacobson, B.S. Dennis, S. Dierker, W.C. Sinke and F. Spaepen, Solid St. Comm. 75, 197 (1990)

[15] B. Nilsen, C.J. Tsal, H.A. Atwater and K.G. Lynn, to be published. 

